\title{
SOBRE A ANÁLISE DE ENUNCIADOS PRÁTICOS EM ERNST TUGENDHAT
}

\author{
ON THE ANALYSIS OF PRACTICAL STATEMENTS IN ERNST TUGENDHAT
}

\author{
MARCOS FANTON \\ (PUCRS / Brasil)
}

\begin{abstract}
RESUMO
Este trabalho tem por objetivo avaliar um aspecto formal da filosofia de Ernst Tugendhat, qual seja, o modo e o resultado de sua análise dos enunciados práticos. Na medida em que a semântica formal tem a pretensão de elaborar uma concepção sistemática de filosofia analítica da linguagem, ela engloba a investigação tanto de sentenças assertóricas quanto de sentenças práticas através de um conceito específico de análise. Além disso, Tugendhat é a favor da tese de que o método analítico-linguístico é o único método correto para se tratar de questões filosóficas. Nesse sentido, tal posição filosófica precisa dar conta do modo de agir prático e moral do ser humano dentro de limites estritamente semânticos, caso contrário passará a desenvolver tal temática de maneira ametódica e indeterminada. Assim, este trabalho surge da suspeita da violação, por parte de Tugendhat, de seus próprios requisitos metodológicos na análise de enunciados práticos, que acaba admitindo, em último caso, pressupostos antropológicos, psicológicos e/ou sociológicos na sua investigação.
\end{abstract}

Palavras-chave: Filosofia analítica da linguagem. Ernst Tugendhat. Análise. Enunciados práticos.

\begin{abstract}
This paper aims to evaluate a formal aspect of Ernst Tugendhat's philosophy, which is, the mode and the results of its analysis of practical statements. Insofar as formal semantics has claimed the development of a systematic conception of analytic philosophy of language, it embraces the investigation of both assertoric and practical sentences through a specific concept of analysis. Moreover, Tugendhat claims that the analytical method is the only proper method for dealing with philosophical subjects. Accordingly, this philosophical paradigm must develop an account of the practical and moral human agency, strictly within its semantic limits, otherwise it will proceed in an undetermined and amethodical manner. Thus, this work rises from the suspicion of the violation by Tugendhat of its own methodological requirements in the analysis of practical statements, which, in the last case, ends up admitting anthropological, psychological and/or sociological assumptions in his research.
\end{abstract}

Keywords: Analytical philosophy of language. Ernst Tugendhat. Analysis. Practical statements.

A filosofia analítica da linguagem, de uma maneira geral, parte da afirmação de que o modo como conhecemos ou nos relacionamos com objetos deve ser explicado através do modo como compreendemos expressões linguísticas, sentenças ou mesmo uma linguagem como um todo. Segundo a famosa definição de Dummett, o giro linguístico admite dois "axiomas": "em 
primeiro lugar, que uma descrição filosófica do pensamento pode ser obtida através de uma descrição filosófica da linguagem, e, em segundo lugar, que uma descrição plausível pode ser obtida apenas assim" (DUMMETT, 1996, p. 4). Do mesmo modo, ao elaborar uma concepção de filosofia analítica da linguagem, Tugendhat concebe a pergunta "como se compreende uma sentença?" como a pergunta fundamental da filosofia, pois é através dela que abordagens tradicionais, como a ontologia e a filosofia da subjetividade, são substituídas por uma investigação semântica sistemática e convergente. Essa nova disciplina é batizada pelo autor de semântica formal, encarregada de esclarecer as "pressuposições universais de toda compreensão" (TUGENDHAT, 2006, p. 146).

O modo de investigação da semântica formal, desenvolvido em uma das principais obras do filósofo, as Lições introdutórias à filosofia analítica da linguagem (doravante, Lições), baseia-se no seguinte "princípio fundamental": "se perguntamos, filosoficamente, sobre o significado de expressões linguísticas, estamos perguntando o que é, em geral ("como tal"), aquilo sobre o que perguntamos quando, pré-filosoficamente, perguntamos sobre o significado de uma expressão particular" (TUGENDHAT, 2006, p. 227). Tal princípio é fruto, no fundo, da reelaboração de algumas teses das Investigações Filosóficas, de Wittgenstein, concebendo a análise de sentenças como uma explicação intersubjetiva dos seus modos de uso. Como fica evidente, a adoção deste tipo de análise exige o cumprimento de alguns requisitos, que são descritos logo abaixo ${ }^{1}$ :

[1] Deve-se utilizar, necessária e exclusivamente, expressões linguísticas para a explicação de expressões linguísticas (p. 76-7);

[2] Não se deve utilizar expressões com o significado pressuposto ou uma metalinguagem (271 e 295);

[3] Deve-se explicar o signo de identidade $\left({ }^{6}=\right.$ "), isto é, a expressão '...é o mesmo que...' ou '...é igual que...' (492, 519 e $545 \mathrm{ss})$;

[4] A explicação deve ser analítica, isto é, resultar em uma tautologia;

[5] Esta tautologia deve ser esclarecedora/informativa, isto é, explicar como a(s) expressão(ões) linguística(s) é(são) usada(s) (p. 347);

[6] A explicação não deve ultrapassar os limites de uma investigação semântica, isto é, não pode recorrer a fenômenos psicológicos, causais, metafísicos, etc. (p. 67 e 235); 
[7] A explicação das expressões linguísticas deve ser compreensível para outros indivíduos (intersubjetiva) (p. 214 e 229).

Tugendhat não chega a listar tais requisitos explicitamente; eles se encontram “espalhados”, digamos assim, nas suas Lições. Porém, é importante mantermos esse quadro em vista, pois iremos realizar uma comparação, mais adiante, com a análise dos enunciados práticos, verificando se esta se mantém nos limites da semântica formal.

Além disso, parto da hipótese de trabalho de que este conceito de análise é empregado por Tugendhat não apenas em suas Lições ([1976] 2006), mas também em Autoconsciência e autodeterminação ([1979] 1993). Segundo esta hipótese, tais obras abrangeriam, assim, a análise das seguintes classes semânticas: [i] sentenças assertóricas sobre objetos perceptíveis (sentenças assertóricas elementares); [ii] sentenças sobre o conhecimento de estados de consciência (o que o filósofo chama de "saber imediato de si mesmo"); [iii] sentenças práticas (analisadas apenas de modo hipotético); e [iv] enunciados práticos. ${ }^{2}$ Com esta hipótese, estou afirmando que ambas as obras anteriormente mencionadas podem ser lidas em conjunto, pois possuem uma conexão implícita do conceito de análise e do método analítico-linguístico.

Em relação à análise de sentenças, as famosas Lições introdutórias à filosofia analítica da linguagem podem ser vistas como uma obra que explica, de uma maneira sistemática e minuciosa, como compreendemos sentenças assertóricas sobre objetos perceptíveis. Em termos simplórios, esta tarefa significa a explicação das condições de possibilidade da nossa compreensão, enquanto sujeitos, de objetos perceptíveis, que se daria ao estabelecermos as condições de uso nas quais determinadas sentenças são verdadeiras ou falsas. Todo indivíduo que assere uma sentença como "O sofá é azul”, por exemplo, está erguendo uma pretensão de verdade, ou seja, ele, no fundo, está enunciando "é verdadeiro que o sofá é azul”, pois consegue decidir qual a situação de verificação da referida sentença. ${ }^{3}$ Dentro do quadro da semântica formal, isso significa que o sujeito pode identificar a localização espaço-temporal pela qual o termo singular 'o sofá' está e verificar se o termo geral classificatório 'é azul' aplica-se corretamente ao primeiro (TUGENDHAT, 2006, p. 556-7). 
Devido às suas características semânticas particulares, o modo de uso dos enunciados práticos não é o mesmo das sentenças assertóricas. Como compreendemos o enunciado 'É bom viver de maneira honesta' ou 'Deve-se fazer ações altruístas' ou, ainda, 'Matar é mau'? E quando podemos dizer que tais enunciados são "verdadeiros"? No final de suas Lições, Tugendhat dá uma definição prévia de enunciados práticos, que tomarei como base para o início da discussão:

\begin{abstract}
Naturalmente, não se deve confundir o que aqui eu chamo sentenças [Sätze] práticas com os enunciados [Aussagen] práticos [...]. A análise dos enunciados práticos, sentenças sobre o que é bom, seria apenas o passo subsequente, o passo que se daria depois da análise das sentenças práticas simples. Os enunciados práticos [...] são, naturalmente, os mais desorientadores; eles são híbridos teórico-práticos. Enquanto enunciados, eles contêm uma pretensão de verdade ou de justificação, mas o que é asserido com eles como objetivamente justificado, como racional, é que algo deva ser desejado ou feito. (TUGENDHAT, 2006, p. 581).
\end{abstract}

No contexto desta obra, as sentenças práticas são determinadas como uma classe de sentenças particulares, cujos termos singulares identificam (qualitativamente) indivíduos racionais livres, através dos termos dêiticos correspondentes, como 'eu', 'tu' e 'ele', e cujos termos gerais classificam ações intencionais no futuro ou, também, intenções (TUGENDHAT, 2006, p. 125-6 e 580). Exemplos desta classe de sentença são os seguintes: 'Eu irei almoçar depois do jogo', 'Você virá comigo ao teatro?' ou, ainda, 'Não faças mais isso!'. O modo como suas condições de verdade são explicadas é deixado em aberto por Tugendhat e, apenas como hipótese, o filósofo indica a necessidade da reformulação linguística do conceito de desejar (TUGENDHAT, 2006, p. 582). Os enunciados práticos, por sua vez, são determinados como atos linguísticos e identificados a partir das expressões 'é bom/é melhor', 'ter de', 'dever' e 'querer'. 'É bom viver de maneira responsável', 'Eu quero ser jornalista' ou 'Não deves matar' são exemplos dessa classe semântica.

De maneira resumida, poder-se-ia dizer o seguinte: se as sentenças assertóricas elementares caracterizam-se pela sua situação de verificação como condição-de-verdade, os enunciados práticos, pelo contrário, não possuem tal situação espaço-temporal, pois são usados de outro modo (e para outros fins). Quem enuncia um enunciado prático não ergue uma pretensão de verdade, mas uma pretensão de justificação, que, em um último momento, pode ser universal e objetiva. Assim, quando alguém diz "Não deves matar", ele está iniciando um diálogo consigo 
mesmo e/ou com outro ser racional e livre para fazer ou não fazer a referida ação: "Como posso justificar que quero ou devo matar alguém? Isso é bom para mim ou para os outros indivíduos?"

Essa diferença é percebida também no operador teórico das duas classes semânticas em questão: a sentença assertórica possui o operador "é verdadeiro que..." ou "é o caso que...", enquanto a sentença prática possui o operador "seja o caso que..." e o enunciado prático, "É bom que..." ou "Deve-se...". Nesse sentido, além de negar a existência de fatos morais (TUGENDHAT, 2009, p. 14), Tugendhat também recusa a assim chamada "falácia naturalista", que, em termos semânticos, significa: de uma sentença teórica não se segue uma sentença/enunciado prática/o (TUGENDHAT, 2009, p. 96).

Esse modo de uso das sentenças e dos enunciados práticos pressupõe a noção de liberdade, sendo considerada por Tugendhat uma condição formal para tal classe semântica (TUGENDHAT, 2006, p. 127). Somente falamos "É bom que p" ou "Não devemos $q$ ", porque já há um âmbito de possibilidades de diferentes ações $(p, q, r, s, t, \ldots)$ que podemos escolher. ${ }^{4}$ Caso fôssemos obrigados a escolher ou escolhêssemos impulsivamente apenas $p$, qual a necessidade de afirmar ou perguntar sobre a sua bondade? Por isso, todo enunciado prático deve ser entendido como a resposta a uma pergunta prática do tipo 'O que devo fazer?' ou 'O que nós, como seres racionais e livres, desejamos ou devemos desejar?'. Realizar tais perguntas e tentar dar uma resposta racional a elas é denominado por Tugendhat de deliberação (TUGENDHAT, 2006, p. 127 e 1993, p. 153).

De acordo com a proposta analítica de Tugendhat, estas características mostram que o uso de enunciados práticos tem a função de justificar nossas ações e desejos a outrem, trazendo à tona, ao mesmo tempo, a questão sobre o sentido de uma vida boa (uma das dimensões da moral). Então, por ora, analisar enunciados práticos significa saber como utilizamos enunciados para justificar a nossa concepção de vida boa a outros seres racionais e livres (isto é, uma legitimação absoluta). ${ }^{5}$ Em termos semânticos, questionamo-nos a respeito da conexão entre as expressões linguísticas 'Eu' / 'Todos' e '...devo/devem fazer p' e das consequências do operador teórico 'É bom’ para a análise semântica.

Em termos mais gerais, podemos perceber que a questão subjacente a esta classe de sentenças relaciona-se ao problema da liberdade e da racionalidade em nosso agir prático e moral. Como nossas decisões são tomadas? Como justificamos para outros a nossa concepção de uma vida boa? E esta precisa ser justificada? Descrever essa dimensão reflexiva do ser humano fará 
Tugendhat recorrer a uma espécie de "mecanismo" ou "estrutura", denominado por ele, a partir da tradição conhecida como "existencialismo", de relacionar-se de si consigo mesmo [Sichzusichselbstverhalten]. ${ }^{6}$ Este é o conceito fundamental para compreendermos o modo como Tugendhat analisa os enunciados práticos e é um dos motivos pelos quais ele extrapolou seu método analítico-linguístico.

A análise das sentenças assertóricas elementares culminou, nas Lições, com a elaboração de um complexo mecanismo, que Tugendhat denomina "mecanismo de identificação espaçotemporal". A função teórica deste conceito (ou "estrutura", se podemos dizer assim) é, em último caso, a de possibilitar a identificação da situação de verificação da verdade ou falsidade de sentenças sobre objetos perceptíveis. Através dele, o falante ou o ouvinte podem confirmar se determinado predicado é aplicado corretamente a determinado objeto de sua percepção, que é identificado por um termo singular. Agora, em relação à análise da classe semântica utilizada no contexto do agir e deliberar humano, Tugendhat formula um mecanismo análogo, o já mencionado relacionar-se de si consigo mesmo, que será a condição formal, segundo o autor, para a racionalidade e a liberdade (1993, p. 278). Tal conceito, central no contexto da obra Autoconsciência e autodeterminação, é fruto de uma reelaboração de conceitos similares em Freud, Kierkegaard, Heidegger, Mead e Hegel. Esse conjunto de autores será lido e interpretado à luz do método analítico-linguístico e servirá para explicitar o modo de uso de enunciados práticos. Um dos trechos decisivos para compreendermos a análise dessa classe de enunciados é o seguinte, extraído da obra recém-citada:

\footnotetext{
Não obstante, deve dar-nos o que pensar o fato de que precisamente quando a pergunta prática se formula de maneira fundamental, não é formulada usando a palavra 'bom', senão que se pergunta: quem ou como quero ser. Claro que a pergunta pode ser formulada sempre assim: "O que é, para mim, o melhor que posso fazer?". No entanto, se em uma decisão vital concreta, pedimos conselho a alguém a esse respeito, essa pessoa vai dar, primeiramente, razões, mas, ao final, vai me dizer: "é tua vida e somente tu podes decidir o que é melhor para ti, somente tu podes decidir quem queres ser". Então, há, na deliberação, um ponto culminante, no qual já não podemos justificar objetivamente a decisão, mas que o melhor para mim constitui-se somente em meu querer. (...) Se não fosse assim, se o querer pudesse, em última instância, apoiar-se sobre razões, a vontade perderia, em certa maneira, sua força de gravidade, sua seriedade e isto
} 
significaria que já não seria minha tomada de posição (TUGENDHAT, 1993, p. 187, Itálicos adicionados, MF).

É com esta citação que encontramos, de maneira extremamente sintética, o esclarecimento do estatuto teórico do conceito de querer e de vontade e, também, o final da análise dos enunciados práticos, que seria desenvolvida até o esclarecimento deste "ponto culminante" da deliberação, isto é, até o final da possibilidade de justificação dos enunciados práticos.

Se antes Tugendhat determinou os enunciados práticos através de sua pretensão de justificação objetiva - ao contrário da simples preferência subjetiva -, nesta citação, contudo, o autor não apenas faz uma ressalva, como admite uma inversão de prioridade nestes dois tipos de pretensões. Não é a partir da explicação de enunciados objetivos que devemos iniciar a análise dos enunciados práticos, como, por exemplo, 'Não se deve matar' ou 'É bom viver honestamente', mas, sim, a partir da explicação de enunciados subjetivos, como 'Eu não quero matar ninguém' ou 'Eu desejo viver honestamente'. Quais as principais conseqüências teóricas desse tipo de inversão?

Em primeiro lugar, podemos perceber que, agora, admite-se apenas um termo singular para o enunciado que expressa esse relacionamento de si consigo mesmo do sujeito: o 'eu'. Este é insubstituível, pois apenas com este termo o enunciado conserva seu caráter prático; enunciados com 'ele', por exemplo, são apenas constatativos, isto é, assertóricos ("Para ele, viver honestamente é algo bom") (TUGENDHAT, 1993, p. 144). Em segundo lugar, o termo 'eu' não deve ser entendido como a possibilidade de identificação espaço-temporal de determinado objeto, o que remeteria à explicação dos termos singulares relacionados, como 'ele' e 'tu'. $\mathrm{O}$ 'eu' presente em enunciados práticos refere-se à identidade qualitativa do indivíduo, que diz respeito ao seu modo de relacionamento volitivo-afetivo com a vida (ou existência). Assim, não utilizamos o 'eu' para nos identificarmos espaço-temporalmente, mas para expressarmos quem somos e como queremos ser. A escolha desta identidade é preenchida com a escolha de determinado predicado, 'p', 'q', 'r' ou 's', que só é aplicado corretamente ao termo singular se o falante realmente quer ' $\mathrm{p}$ '.

Além disso, a multiplicidade de atividades possíveis para o indivíduo realizar (expressas por diversos enunciados práticos) não se dá no vazio ou somente após deliberações, mas, segundo Tugendhat, "já sempre” em uma "situação prática global”. Esta situação, que o autor denomina de mundo (a nível subjetivo) ou de sociedade (a nível intersubjetivo), mostra que, por um lado, a 
escolha de determinada atividade ou de determinado modo de existência nunca se dá sem a negação de diversas(os) outras(os), e, por outro lado, que já sempre escolhemos determinada atividade ou determinado modo de existir, seja deliberando sobre ela(e) seja aceitando justificações da tradição ou de terceiros. Assim, todo enunciado prático é um ato que pressupõe essa situação prática e que não precisa de uma deliberação prévia, pois o indivíduo já se relaciona com ela de maneira volitivo-afetiva. Com o enunciado 'Eu quero fazer $p$ ', o sujeito já expressa uma valoração de $p$ : a de que $p$ é bom para sua vida. É a partir deste momento inicial que o falante poderá perguntar se ele realmente quer $p$. Portanto, é este componente subjetivo e volitivo-afetivo que possibilita o início de uma justificação de $p$, isto é, de uma troca de razões entre os demais indivíduos acerca da bondade de $p$.

Ainda que não tenhamos descrito esse mecanismo do relacionar-se de si consigo mesmo em toda sua extensão, já encontramos elementos suficientes para testar a análise de enunciados práticos através do método analítico-linguístico de Tugendhat descrito no início de nosso artigo. Vejamos como ficaria a análise de um enunciado qualquer:

"É bom fazer $p$ " se e somente se:

[i] O sujeito $S$ encontra-se em uma situação prática em que $p$ é uma das possíveis atividades para se fazer;

[ii] $S$ quer fazer $p$;

[iii] $S$ pode fazer $p$ e só depende de sua vontade fazê-lo;

[iv] $S$ delibera sobre fazer $p$;

[v] Ao deliberar, $S$ pergunta se realmente quer fazer $x$ e quais as razões para fazer isso e não fazer $w, y$ ou $z$;

[vi] $S$ troca razões, real ou hipoteticamente, com outros indivíduos sobre fazer $p$;

[vii] $S$ é capaz de justificar diante de qualquer indivíduo que fazer $p$ é melhor do que fazer $w, y$ ou $z$ 
[viii] Esta deliberação de $S$ guia-o em sua escolha de fazer $p$, isto é, a realização de $p$ não é fruto de atos compulsivos.

Mesmo com esta análise rudimentar, a primeira impressão que temos é a de que quase todos os requisitos metodológicos enumerados no início do artigo foram rompidos por Tugendhat: a explicação de um enunciado prático não utiliza apenas expressões linguísticas, mas utiliza, também, um componente volitivo-afetivo (que é subjetivo), ultrapassando, assim, a investigação semântica e incorporando elementos descritivos da antropologia, psicologia e sociologia. Portanto, rompem-se os requisitos [1], [2] e [6]. Além disso, não há a identidade entre analysandum e analysans, ou seja, o conteúdo proposicional dos enunciados não é o mesmo quando dois sujeitos o enunciam, tendo em vista que cada sujeito poderá compreender, a partir da relação com sua própria existência, que $p$ é bom ou mau ou menos preferível que $w$ ou $y$ (quebra do requisito [3]). Desse modo, a análise não será tautológica (requisitos [4] e [5]). Por fim, a explicação possui um componente subjetivo, que não é - e nem poderia ser - intersubjetivo, que é o aspecto volitivo-afetivo (requisito [7]). ${ }^{8}$

Diante deste panorama, podemos admitir, como conclusão, que a análise de enunciados práticos realizada por Tugendhat não é uma análise semântico-formal (ou, ao menos, estritamente semântico-formal). Seria até mesmo de se questionar o que o filósofo entenderia, aqui, por 'análise' e, principalmente, por 'análise semântica de atos linguísticos' - conforme sua definição de enunciado prático.

Através dessas observações, podemos encontrar, também, um fio condutor interpretativo que nos mostra, em um primeiro momento, como o autor passou a relativizar gradativamente a posição da linguagem nas suas obras posteriores (e, consequentemente, a função do conceito de análise). Em Lições sobre ética, Tugendhat limita-se a apontar que "a filosofia não pode fazer nada mais do que analisar adequadamente, em suas pressuposições, uma pré-compreensão existente" ([1993] 2009, p. 28), deixando em aberto o que isso significaria no presente contexto. Posteriormente, em Antropologia como filosofia primeira, o filósofo afirma que a "estrutura do entendimento humano" não pode ser reduzida ao "entendimento linguístico", ainda que a linguagem ocupe um lugar central. É aqui que a questão central de sua filosofia analítica, "Como compreendemos uma sentença?", é substituída por outra: “Quem somos nós, seres humanos?”, tornando a investigação filosófica, com isso, uma investigação antropológica das estruturas de 
nossa existência e de nosso entender a partir da primeira pessoa (2006, p. 86). ${ }^{9}$ Contudo, não é sem surpresa que podemos perceber, nesta última fase da filosofia de Tugendhat, uma nova elaboração da estrutura do relacionar-se de si consigo mesmo, fundamental para a análise de enunciados práticos, quase vinte anos após a publicação de Autoconsciência e autodeterminação, na obra Egocentricidade e mística: um ensaio antropológico (1997 [2004]). Portanto, é nesta transição (da filosofia analítica da linguagem para a antropologia filosófica) que podemos perceber, com maior clareza, os limites de suas obras precedentes. E este tipo de modificação da dimensão teórica pode significar duas coisas: ou Tugendhat está falando sobre estruturas completamente distintas ou ele realizou uma reavaliação de sua obra anterior, ainda que implicitamente. E, se a segunda opção for o caso, ela corrobora com o resultado do presente artigo, dando-lhe uma consistência ainda maior, o que significaria dizer que grande parte dos conceitos elaborados em Autoconsciência e autodeterminação, encarregada de descrever o modo de agir do ser humano através da análise de enunciados práticos, não está restrita ao âmbito analítico-linguístico e requer uma determinação teórica mais precisa (como Tugendhat parece sugerir em suas obras mais recentes). 


\section{Notas}

\footnotetext{
${ }^{1}$ Todas as referências das condições de análise referem-se à obra Lições introdutórias à filosofia analítica da linguagem (2006).
}

${ }^{2}$ Tugendhat realiza uma distinção, presente apenas em suas Lições, entre sentenças e enunciados. As primeiras são consideradas as menores unidades de significado, constituídas por uma forma sentencial e um conteúdo proposicional, ao passo que os enunciados são atos lingüísticos, isto é, são enunciações de sentenças. Como veremos mais tarde, os enunciados práticos não podem ser compreendidos como sentenças, devido ao fato de sempre pressuporem um ato lingüístico de determinado falante.

${ }^{3}$ Para Sofia Stein, Tugendhat realiza uma espécie de "fusão" pouco usual na tradição analítico-linguística entre as condições-de-verdade e o modo de uso das sentenças assertóricas. STEIN, Sofia, 2007.

${ }^{4}$ Em Autoconsciência e autodeterminação, Tugendhat denominará esse âmbito de liberdade, a nível individual, de mundo, e, a nível intersubjetivo, de sociedade.

${ }^{5}$ A legitimação de determinada ação (ou determinada concepção de vida boa) é absoluta quando "(a) ela não é realizada em relação a uma regra dada e, consequentemente, também (b) não perante a parceiros particulares, mas diante de quaisquer parceiros (e, neste sentido, é “objetiva”)". Este conceito é contrastado com o de legitimação relativa, que é, portanto, conforme uma regra e/ou justificada apenas diante de determinados parceiros (Tugendhat, 2006, p. 132).

${ }^{6}$ Denomino de "mecanismo" por uma questão de analogia com o mecanismo de identificação espaço-temporal presente nas Lições (2006, p. 487). Já o termo “estrutura” aparecerá em Egocentricidade e mística (2004), mas já com uma abordagem explicitamente antropológica.

${ }^{7}$ Esta pode ser considerada a análise mais comum do termo 'eu', presente em sentenças assertóricas ou sobre estados mentais. Para tanto, ver Tugendhat, 1993, cap. 3-6, principalmente, páginas 67ss.

${ }^{8}$ A quebra dos requisitos [1], [6] e [7] poderiam ser mitigados com a concepção não-dogmática do princípio de Wittgenstein, elaborada de maneira programática nas Lições. Ali, Tugendhat afirma o seguinte: "Alcançamos uma tal concepção não-dogmática do princípio de Wittgenstein, na medida em que consideremos não apenas a possibilidade de alguém esclarecer para si mesmo o modo de uso de uma expressão, da mesma forma que ele a explicaria para outro, mas também admitamos, como um caso limite, a possibilidade de que possam existir significados ou componentes de significado de expressões que alguém pode esclarecer apenas para si mesmo". Contudo, essa concepção teria de ser desenvolvida, a fim de acomodar o modo de análise dos enunciados práticos.

${ }^{9}$ Sobre essa transição, ver STEIN, 2007. 


\section{Referências Bibliográficas}

DUMMETT, M. Origins of analytical philosophy. Cambridge, Massachusetts: Harvard University Press, 1996.

STEIN, Sofia. "Semântica formal e empirismo: o diálogo de Tugendhat com a tradição analítica". In: DALL'AGNOL, Darlei (Org). Verdade e respeito: a filosofia de Ernst Tugendhat. Florianópolis: EUFSC, 2007.

STEIN, Ernildo. "Da analítica da linguagem à antropologia filosófica". In: DALL'AGNOL, Darlei (Org). Verdade e respeito: a filosofia de Ernst Tugendhat. Florianópolis: EUFSC, 2007.

TUGENDHAT, Ernst. Autoconciencia y autodeterminación: una interpretación lingüísticoanalítica. Trad.: Rosa Helena Santos-Ihlau. México: FCE, 1993.

. "Antropologia como filosofia primeira". In: OLIVEIRA, Nythamar de; SOUZA, Draiton Gonzaga de. Hermenêutica e filosofia primeira: Festschrift para Ernildo Stein. Ijuí: Unijuí, 2006.

. Egocentricidad y mística: un estudio antropológico. Trad.: Maurício Suárez Crothers. Barcelona: Gedisa, 2004. 2006.

Lições introdutórias à filosofia analítica da linguagem. Trad. Ronai Rocha. Ijuí: Unijuí, . Lições sobre ética. Petrópolis: Vozes, 2009. 